\title{
Microbiological quality of poultry meat: a review*
}

Author(s)

Mead GC

Consultant

Mail Address

GC Mead

17 Harbutts, Bathampton, Bath, Somerset, BA2 6TA, UK

E-mail: geoffmead@hotmail.com

\section{Keywords}

Poultry meat, processing, microbial contamination

* Based on a paper presented at the World Poultry Congress, Istanbul, Turkey, 2004.

\section{ABSTRACT}

Poultry meat can be contaminated with a variety of microorganisms, including those capable of spoiling the product during chill storage, and certain foodborne pathogens. Human illness may follow from handling of raw meat, undercooking or mishandling of the cooked product. While Salmonellaand Campylobacterspp. remain the organisms of greatest global concern in this respect, others present include the more recently reported Arcobacter and Helicobacter spp. and, occasionally, verotoxigenic Escherichia coli. Also considered here is the growing problem of antimicrobial resistance among poultry-associated pathogens.

Because of the need for a systematic and universally applicable approach to food safety control, the Hazard Analysis Critical Control Point (HACCP) concept is increasingly being introduced into the Poultry Industry, and Quantitative Risk Assessment (QRA) is being applied to microbial hazards. Among a number of completed and on-going studies on QRA are those undertaken by FAO/WHO on Salmonella and Campylobacter in broilers. In the case of Campylobacter, however, any QRA must assume at present that all strains have the same pathogenic potential for humans and comparable survival capabilities, even though this is unlikely to be the case.

Implementation of the HACCP system in poultry processing plants addresses zoonotic agents that are not detectable by conventional meat inspection procedures and can help to control contamination of carcasses with spoilage organisms. The system brings obvious benefits in optimising plant hygiene, ensuring compliance with legislation and providing evidence of 'due diligence' on the part of the processor. It is now being applied globally in two different situations: in one, such as that occurring in the USA, carcass contamination is clearly reduced as carcasses pass through the process and are finally chilled in superchlorinated water. There is also the option to use a chemical-rinse treatment for further reduction of microbial contamination. In the second scenario, processors in the EU are not allowed to super-chlorinate process water, and water chilling, which has an important washing effect, is confined to carcasses intended for freezing. Also, chemical decontamination is prohibited until 2006 at the earliest. Therefore, for fresh carcasses that are air chilled, there is presently no marked reduction in carcass contamination and no Critical Control Point at which a significant reduction in pathogen contamination can be guaranteed. Overall, effective control of the organisms is best realised through a farm-to-fork approach at all stages of the supply chain.

\section{INTRODUCTION}

The microbiological safety and quality of poultry meat are equally important to producers, retailers and consumers, and both involve 
microbial contaminants on the processed product. Two quite different groups of microorganisms are relevant: on the one hand certain foodborne pathogens, as discussed below, and, on the other, organisms that are generally harmless to human health, but, being psychrotrophic, are able to multiply on the product during chill storage. Spoilage results mainly from 'off'odour development, and product shelf-life is determined both by the number of spoilage organisms present initially and the temperature history of the product at all stages of production and subsequent storage and handling (Pooni \& Mead, 1984). For chillstored poultry, Viehweg et al. (1989) demonstrated that virtually all the odorous substances found at spoilage could be attributed to microbial growth and metabolism.

Contamination of poultry meat with foodborne pathogens remains an important public health issue, because it can lead to illness if there are malpractices in handling, cooking or post-cooking storage of the product. In developed countries, foodborne illness causes human suffering and loss of productivity, and adds significantly to the costs of food production and healthcare. It is also a possible cause of mortality, which is even more of a problem in developing regions, where the health status of many individuals is already compromised. Numerically, the most important agents are Salmonella and Campylobacter spp. Data for the European Union (EU) show that in 2001, there were 157822 reported cases of human salmonellosis and 156232 cases of Campylobacter enteritis (Cavitte, 2003), although both diseases are known to be underreported, and the true figures are likely to be considerably higher. While poultry is by no means the only source of the causative organisms, it is widely recognised as a major reservoir in each case, due to symptomless carriage in the live bird (Table 1). The problem is exacerbated by modern conditions of intensive rearing, where large numbers of birds are kept together, and high-rate processing, in which carcasses remain in close proximity throughout the operation. Such conditions favour the spread of any pathogens that may gain access to the flock. Moreover, the use of antimicrobials in poultry production, whether for prophylactic, therapeutic or performanceenhancing purposes, contributes to the development of resistance in pathogens, which is increasing, and can have serious consequences for the treatment of human illness from these organisms. With salmonellosis, for example, the testing of 27000 isolates from human cases in ten European countries in 2000, showed that almost $40 \%$ were resistant to at least one antimicrobial, while 18\% were multiresistant (Threlfall et al., 2003). Multiple resistance was most often observed in serotype Typhimurium, including DTs 104 and 204b, and 51\% of Typhimurium strains were in this category. Serotypes from humans with multiple resistance include those that are also found in poultry, of which SParatyphi B variant Java is the most recent example. In the Netherlands, variant Java had increased in poultry from less than $2 \%$ of isolates before 1996 to $60 \%$ in 2003 (van Pelt et al., 2003). The resistance of Campylobacter to antimicrobials is also rising, especially to fluoroquinolones, which have been widely used in both human and veterinary medicine.

Although Salmonella and Campylobacter spp. are the predominant foodborne pathogens associated with poultry and are frequently implicated in human illness from this source, other pathogens also occur, including Clostridium perfringens, Escherichia coli 0157 and Listeria monocytogenes, together with those recognised more recently, such as Arcobacter and Helicobacter spp. (Corry \& Atabay, 2001). This review will consider the more important contaminants of poultry meat in relation to product safety and shelflife. Also discussed is the present status of control measures, including application of the Hazard Analysis Critical Control Point (HACCP) system and the benefits likely to arise from the use of Quantitative Risk Assessment as a management tool in the control of foodborne pathogens.

\section{Salmonella and Campylobacter}

Contamination of poultry carcasses and parts with these organisms is well documented and data are available for many parts of the world (e.g. Waldroup 1996; Simmons et al., 2003), although inter-country comparisons are not usually possible, because of differences in sampling and methods of testing. Most salmonellas found on poultry meat are non-hostspecific and are considered capable of causing human food poisoning. The thermophilic campylobacters are mainly $C$. jejuni, which is the principal cause of human campylobacteriosis, but other, so-called 'campylobacteria' also occur frequently, and include species of Arcobacterand Helicobacter pullorum. Their potential for causing human illness has been discussed by Corry \& Atabay (2001). For processed poultry, both the proportion of positive samples and the number of organisms present per unit sample is greater for Campylobacter than it is for Salmonella, reflecting the greater colonising ability and higher level of intestinal 
carriage at slaughter (Table 1), which can be up to $10^{9}$ $\mathrm{cfu} / \mathrm{g}$. With Salmonella, there is wide variation in the incidence of positive carcasses, but counts rarely exceed 100 cfu / carcass, well below the level normally associated with food poisoning. However, both types of bacteria include strains that are invasive in poultry and can penetrate internal organs or deep tissues of the bird, where the organisms may be less readily destroyed by cooking. On the surface, campylobacter contamination tends to be relatively high, up to $10^{9}$ cfu / carcass. Since the infective dose is only a few hundred viable cells, illness can easily result from handling raw poultry without suitable hygiene precautions, and is a potential hazard for new staff in poultry processing plants.

Table 1 - Features of intestinal carriage in Campylobacter and Salmonella spp.

\begin{tabular}{lcc} 
Feature & Campylobacter & Salmonella \\
\hline Host susceptibility & not age-related & age-related \\
Preferred site & caeca & caeca \\
Preferred niche & mucus in crypts & none \\
Colonisation type & persistent & transient/intermittent \\
Carriage level & relatively high & variable \\
Invasiveness & some strains & some strains \\
Colonisation genes & some identified & some identified \\
\hline
\end{tabular}

Salmonellas survive well in the environment, but campylobacters appear less well-adapted to survival outside the alimentary tract of warm-blooded animals. Also, growth only occurs under conditions of high moisture, reduced oxygen and an environmental temperature above $30^{\circ} \mathrm{C}$. The organisms are particularly sensitive to drying and the effects of freezing and thawing, which can cause a $1-2 \log$ reduction in the level of contamination on poultry meat. However, campylobacters have many different hosts, they colonise at high levels and therefore are shed into the environment in large numbers. There is still much debate about possible survival mechanisms outside the host, including the ability to exist in a supposedly dormant form, in which the organisms appear to be viable, but non-culturable by conventional methods. From the practical viewpoint, campylobacters can persist as contaminants of poultry products throughout the entire supply chain and remain detectable by cultural methods. A key factor in their survival may be their attachment to, or entrapment in, poultry tissues during carcass processing. In this situation, their resistance to adverse conditions, like that of other bacteria, is significantly increased. Thus, the organisms can survive on carcasses during processes such as scalding, washing and water chilling, that might otherwise remove or destroy them.

\section{Clostridium perfringens}

As a cause of human food poisoning, this is not among the more dangerous pathogens. It is, however, a spore-forming organism and some strains produces spores that are unusually heat-resistant. Therefore, unlike vegetative bacterial cells, the spores are not necessarily destroyed by normal cooking and may subsequently germinate and outgrow to hazardous levels, if post-cooking storage is inadequate. In fact, most outbreaks involve strains that produce the more heat-resistant spores. In a survey of food-poisoning outbreaks associated with poultry in England and Wales during 1992 - 1999, Cl. perfringens was found to be responsible for $21 \%$ of the outbreaks, second only to Salmonella as a causative agent (Kessel et al., 2001). In some instances, the problem arose from consumption of contaminated turkey at Christmas time, when storage of the larger, whole carcasses used for festive meals appears to have been at fault. The organism is an obligate anaerobe that is relatively tolerant to oxygen and can be found in low numbers in the alimentary tract of poultry. When present in meat crevices etc, growth is favoured by conditions in which oxygen has been dispelled by cooking. However, since growth of the organism cannot occur if the meat is held below $15^{\circ} \mathrm{C}$, the problem is easily avoided by refrigerated storage.

\section{Escherichia coli 0157}

Verocytotoxin-producing strains of E. coli (VTEC), cause diarrhoea and haemorrhagic colitis in humans and can lead to potentially life-threatening sequelae, such as haemolytic uraemic syndrome and thrombotic thrombocytopaenic purpura. Although VTEC strains occur in a wide range of $O$ serogroups, the most important in human disease is 0157, which accounts for almost all major foodborne outbreaks in Europe and the USA. In England and Wales, the first case involving this organism occurred in 1982 and reported cases have increased steadily since then, reaching a peak of 1087 in 1997 (PHLS data). While VTEC 0157 is mostly found in ruminant animals, it is occasionally associated with other livestock and various foods of animal origin. To what extent is the organism a matter of concern in relation to poultry? An outbreak in the UK that was associated with eating turkey roll was reported by Salmon et al. (1989) and two further outbreaks linked 
to chicken dishes were mentioned by Kessel et al. (2001). With all three, however, cross-contamination in the kitchen was suspected ( $\mathrm{Dr}$ I A Gillespie, personal communication). Experience suggests that VTEC 0157 is rare in poultry, whether in live birds or on processed products, and, when it has been found, tests for the necessary virulence factors have not always been carried out. On the other hand, strains lacking Shiga toxin genes have been isolated form patients with typical disease symptoms (Schmidt et al., 1999).

In an early survey of retail meats in the USA, Doyle and Schoeni (1987) found VTEC 0157 in 1.5\% of 263 samples of chicken and turkey leg meat. Although Heuvelink et al. (1999) could find no VTEC 0157 in chicken faeces, $1.3 \%$ of 459 pooled samples from turkeys were positive and one isolate contained genes for type 2 verotoxin, attaching-and-effacing capability and the relevant haemolysin. Because of these virulence factors, the strain appeared capable of causing illness in man. Only turkeys had been kept on the farm in question, so transfer of the strain from other livestock was unlikely. VTEC other than 0157 were found in $12 \%$ of retail chicken samples and $7 \%$ of turkey samples in the USA by Samadpour et al. (1994).

Despite the rarity of VTEC 0157 in poultry, experimental studies have shown that chicks can be readily colonised with a challenge dose as low as 10 cfu / bird (Schoeni \& Doyle, 1994) and colonisation may persist for at least three months. Another study (Stavric et al., 1993) showed that the organism was present, following challenge, on caecal mucosa and in the contents of the lumen. The extent of colonisation depended on dose, age, breed and time after exposure. However, colonisation could be reduced by competitive exclusion (CE) treatment, using a culture of faecal material from a pathogen-free donor bird. Hakkinen \& Schneitz (1996) obtained a four-log reduction in colonisation, when a commercial CE product was used to treat chicks before challenge.

Since VTEC 0157 is capable of colonising poultry without causing illness in the birds, is present in some wild-bird vectors, survives well in soil and is able to grow in chicken manure held at ambient temperatures, it is surprising that the organism is not found more often in commercial broiler flocks. The significance of non0157 VTEC, which also appear to occur in poultry, needs to be further investigated.

\section{Listeria monocytogenes}

The organism is a leading cause of food-related mortality and morbidity in man, and the majority of cases are believed to be foodborne. The symptoms vary widely and those affected are frequently among the most vulnerable groups in society. Nevertheless, despite the common occurrence of $L$. monocytogenes in a variety of foods, human listeriosis is relatively rare, which may be due in part to the high infective dose of ca $10^{9}$ viable cells that appears to be necessary in most cases (Smerdon et al., 2001). The organism is common on raw poultry meat and has been found on chicken, turkey, duck and pheasant. Numerous surveys have shown that more than $50 \%$ of processed chicken carcasses are likely to be positive, although numbers are usually low, even $<1 / \mathrm{cm}^{2}$ of skin.

The health hazard from contaminated, raw poultry is mainly one of cross-contamination in the kitchen, where the organism may spread to cooked foods or other ready-to-eat items, such as salad vegetables. There is also a potential problem with cooked poultry produced commercially. Although normal cooking destroys listerias, recontamination can occur during post-cooking handling at the factory, even with the most rigorous hygiene control. Since pre-cooked items are not necessarily reheated by consumers before being eaten, and the organism is capable of growth under chill conditions, strict microbiological limit values are considered necessary. At one extreme, in the USA, there is zero tolerance for L. monocytogenes in readyto-eat poultry products, and periodical recalls of contaminated product batches have cost many millions of US dollars. A different approach is taken in the UK, and counts of Listeria spp. below $20 \mathrm{cfu} / \mathrm{g}$ are considered 'satisfactory'. In a recent survey of barbecued chicken sampled at retail (Williams et al., 2002), all 221 samples examined were in this category. Such a low level of product contamination does not suggest that any significant growth of the organism had occurred in positive samples.

\section{Spoilage organisms}

When poultry meat is stored aerobically under chill conditions, the organisms that predominate at spoilage are invariably Pseudomonas spp., accompanied by lower numbers of other Gram-negative bacteria (Table 2). Using numerical taxonomy, Arnaut-Rollier et al. (1999) found four major clusters of pseudomonads: Ps fragi, Ps lundensis, Ps fluorescens biovars and an unidentified group resembling Ps fluorescens. Other bacteria that are sometimes present include Shewanella putrefaciens and psychrotrophic strains of Enterobacteriaceae. The above organisms are common in soil and water, and are thought to originate from 
the live-bird environment. Yeasts, too, can be involved in spoilage and may be more important in this respect than was previously thought.

The more recent development of relatively low-cost gas-packaging for poultry has resulted in widespread use of this technology for retail presentation of chilled poultry-meat products. The approach is based on the known inhibitory effects of carbon dioxide atmospheres, in the range $10-30 \%$, on the growth of aerobic spoilage bacteria (Mead, 2004). Under these conditions, a different, slower-growing microflora develops (Table 2), while pseudomonads, in particular, are suppressed. At spoilage, the predominant organisms are usually lactic acid bacteria, but other Gram-positive and Gram-negative bacteria can occur in relatively large numbers.

Table 2 - The principal bacteria and yeasts associated with spoilage of chill-stored poultry meat, either in air or a modified atmosphere (enriched with carbon dioxide).

\begin{tabular}{lc} 
Aerobic storage & Modified-atmosphere storage \\
\hline Pseudomonas & Lactobacillus \\
\hline Acinetobacter & Carnobacterium \\
Moraxella & Brochothrix \\
Psychrobacter & Shewanella \\
& Enterobacteriaceae \\
* Candida & [psychrotrophic strains] \\
* Yarrowia & \\
* Yeasts & \\
\hline
\end{tabular}

\section{Control of product contamination}

For food to be entirely safe from the microbiological viewpoint, it would need to be free from all pathogenic organisms. It is widely recognised, however, that this is not a realistic goal for raw poultry meat. There is still no economically viable means of eliminating foodborne pathogens in poultry-meat production, without the use of ionising radiation, which is presently unacceptable to many consumers. Therefore, some level of product contamination must be tolerated, although this varies widely from one country to another, especially in relation to Salmonella. In Sweden, which has a small poultry industry, the prevalence of Salmonellacontaminated poultry meat has been less than $1 \%$ for many years and the organisms are rarely found in retail samples due to rigorous surveillance and control programmes that are relatively costly to operate (Persson \& Jendteg, 1992). Food from which salmonellas are isolated in Sweden is, by law, considered unfit for human consumption. By contrast, countries with larger, more complex poultry industries find control of Salmonella more difficult and subject to cost constraints. In the UK, improved practices in production and processing have led to a steady decline in the contamination rate, the latest survey of retail chicken showing only $5.7 \%$ of samples positive, in comparison with almost $80 \%$ some 20 years ago (Report, 1996). This can be attributed largely to controls at farm level, especially in relation to $S$. Enteritidis, which, however, has increased in incidence recently (Table 3). Recent data for the USA (Simmons et al., 2003) showed $33.9 \%$ of whole carcasses positive for Salmonella over a 20-week sampling period, which contrasts with the national average of less than $9 \%$ (Shane, 2004). In the USA and many other countries, detection of Salmonella in a particular lot of poultry does not imply that the lot should be condemned for that reason, bearing in mind that the small number of cells usually present on a contaminated item is unlikely to be a direct cause of human illness. Also, regular rejection of contaminated lots would be economically unacceptable on the scale required. Instead, there is a growing emphasis on the application of preventative measures within the Industry and there is now much reliance on the HACCP system for controlling foodborne pathogens in poultry processing.

Table 3 - Changes in incidents of some Salmonella serotypes in British chickens.

\begin{tabular}{lrrrrrrr}
$\begin{array}{l}\text { Incidents (\%) } \\
\text { Serotype }\end{array}$ & $\mathbf{1 9 9 7}$ & $\mathbf{1 9 9 8}$ & $\mathbf{1 9 9 9}$ & $\mathbf{2 0 0 0}$ & $\mathbf{2 0 0 1}$ & $\mathbf{2 0 0 2}$ & $\mathbf{2 0 0 3}$ \\
Enteritidis & 21.0 & 16.6 & 3.2 & 0.9 & 0.8 & 1.3 & 4.5 \\
Typhimurium & 5.8 & 7.5 & 6.7 & 3.5 & 6.1 & 4.1 & 2.0 \\
Senftenberg & 5.6 & 11.4 & 12.4 & 21.6 & 16.7 & 12.3 & 8.8 \\
Livingstone & 1.9 & 3.6 & 6.3 & 4.0 & 8.6 & 14.0 & 15.6 \\
Liverpool & 5.9 & 1.6 & 2.1 & 2.6 & 6.9 & 3.6 & 3.2 \\
Mbandaka & 10.2 & 6.2 & 9.2 & 3.5 & 6.6 & 5.9 & 5.5 \\
\hline Thompson & 6.2 & 5.3 & 5.3 & 6.2 & 6.5 & 3.6 & 1.4 \\
\hline (Data: Veterinary Laboratories & Agency, Weybridge, UK). &
\end{tabular}

The microbiological hazards in the processing operation are well known and are often difficult to control effectively, because of the technological limitations in the process that can lead to crosscontamination of the carcasses being processed. Implementation of the HACCP system does not overcome this drawback, but has a number of clear benefits, including the following:

1. The system ensures regular monitoring of the process as a whole.

2. Hygiene control is optimised, within the above- 
mentioned constraints, thereby providing evidence of 'due diligence' on the part of the processor, as required by UK food law.

3. Checking of control parameters and recording of results are an integral part of the system.

4. Compliance with hygiene legislation is ensured.

5. Staff awareness of food-safety requirements is increased.

6. As a result of national HACCP implementation, operational standards across the Industry become more uniform.

Although use of the HACCP system in poultry processing is aimed primarily at the control of foodborne pathogens, there is also the potential to reduce contamination of carcasses with spoilage organisms. Pseudomonads, in particular, are largely destroyed during scalding and carcasses are recontaminated during subsequent stages of processing (Mead, 2004). It is these stages that need to be targeted for control purposes.

Cross-contamination of carcasses with pathogens can occur at virtually every stage of the process and currently there is little evidence that this problem is significantly reduced by the application of HACCP principles. Also unclear is the effect of the HACCP system on levels of carcass contamination, although this will vary according to the type of process used and permitted intervention measures in different countries. The most effective type of process for reducing contamination is likely to be one in which carcasses are immersion-chilled in chlorinated water and then frozen. In the USA, where water-immersion chilling is the norm and super-chlorination of process water is permitted, there is also the option to use a chemical decontamination treatment for carcasses, which may involve substances such as trisodium phosphate, acidified sodium chlorite or peroxyacetic acid (Russell, 2003). In this respect, there is currently a very different situation in the EU, because superchlorination is not allowed, immersion chilling has been largely replaced by air chilling or evaporative cooling, and any form of chemical decontamination is unacceptable. Therefore, in the case of fresh carcasses that are air chilled, there is no marked reduction in carcass contamination (Allen et al., 2000; Fluckey et al., 2003). Moreover, there is no Critical Control Point at which a significant reduction in pathogen contamination can be guaranteed. However, this unsatisfactory situation may change in 2006 (Report, 2003). Without the use of processing aids to improve hygiene, the greatest reductions in carcass contamination are likely to come from technological developments in the process that are designed to improve hygiene, as long as these are acceptable to the Industry. For example, a process for simultaneous scalding and plucking of broilers, although not adopted commercially, reduced levels of Enterobacteriaceae on carcasses by one hundred-fold in experimental trials (Mulder, 1985). On the other hand, a study aimed at reducing Campylobacter contamination by merely optimising existing processing procedures, achieved much smaller improvements (Mead et al., 1995). Possible benefits from physical carcass decontamination treatments that are being developed to reduce levels of Campylobacter are shown in Table 4.

\begin{tabular}{|c|c|}
\hline Treatment & ${ }^{*} \log _{10}$ reduction \\
\hline Cooling / drying, $20^{\circ} \mathrm{C} /(\mathrm{C})$ & 0.3 \\
\hline $\begin{array}{l}\text { Drying / heating: } \\
30^{\circ} \mathrm{C}, 15 \mathrm{~min}(\mathrm{~S}) \\
40^{\circ} \mathrm{C}, 15 \min (\mathrm{S})\end{array}$ & $\begin{array}{l}1.0-2.0 \\
2.0-3.5\end{array}$ \\
\hline Crust-freezing (C) & 0.4 \\
\hline Steam at $100^{\circ} \mathrm{C}, 12 \mathrm{sec}(\mathrm{C})$ & 2.5 \\
\hline
\end{tabular}

Mandatory use of the HACCP system in US processing plants, which began in 1997, is coupled with performance standards that include a Salmonella prevalence of $20 \%$ for post-chill broiler carcasses (Federal Register, 1996). How cost-effective has this approach been in reducing human salmonellosis? In posing the question, it must be acknowledged that the Salmonella status of processed carcasses depends ultimately on control measures taken on the farm, which are not addressed directly in the legislation. Attempts to meet the requirements of the so-called 'Mega-Reg' have involved a $30-40 \%$ increase in the use of clean water during processing, and overall costs are said to be several times higher than official forecasts (Ollinger \& Mueller, 2003). So far, there is no real evidence that human salmonellosis has fallen in the USA as a result of HACCP implementation. Furthermore, in the year 1999, there were 32782 reported isolations of Salmonella from human cases, increasing to 33310 in 2000 and then decreasing to 31675 in 2001 (CDC data). Thus, the recent situation has been relatively static.

\section{Microbiological risk assessment (MRA)}

MRA is a developing concept, which is complementary to the application of HACCP principles. 
As defined by the Codex Alimentarius Commission (CAC, 1999), it includes hazard identification, exposure assessment, hazard characterisation and risk characterisation. The concept is discussed in relation to poultry by Kelly et al. (2003). It is important not only in quantifying the risk of human illness from a pathogen or microbial toxin associated with poultry, but in determining the extent to which the risk can be reduced by specific intervention measures. Thus, the effect of controlling the hazard at a particular Critical Control Point can be quantified with this approach.

Quantitative risk assessments vary in mathematical complexity, depending on the question being asked. Often, they require a diversity of data that is sufficient to account for any variation that occurs. In practice, data sets are usually far from complete and may be subject to considerable uncertainty. This problem is compounded by the dynamic nature of microbial populations, which undergo continuous change. Dealing with uncertainty has been a feature of the development of MRA and is clearly evident in the case of Campylobacter infections associated with chicken consumption. Here, the true extent to which human cases are derived from eating chicken is unknown, it has to be assumed that all strains of the organism have the same potential to cause human illness and that their pathogenic and survival properties are similar. Also, there is a general lack of data on levels of product contamination at different stages of the supply chain and during subsequent handling prior to consumption. Nevertheless, the MRA described by Kelly et al. (2003) makes some important predictions and highlights the effects of freezing poultry meat, which, more than other mitigation strategies examined, will reduce both the chance and level of subsequent human exposure.

In another recent MRA (Rosenquist et al., 2003), it is predicted that human campylobacteriosis associated with chicken consumption would decrease 30-fold if levels of Campylobacter contamination on carcasses could be reduced by two log units. Alternatively, flock prevalence would need to be reduced by the same factor. Such reductions would require better on-farm control than is possible at present or a highly effective decontamination treatment for processed carcasses. However, a comparable reduction in human illness was also predicted from possible improvements in kitchen hygiene or, again, by freezing the product. As knowledge of Campylobacter in poultry meat production continues to expand, it is likely that further mitigation strategies will become apparent.
Increasingly, risk assessment is being used as a scientific tool to evaluate human health risks from hazardous agents present in foods. In this respect, Munday et al. (2003) have identified 36 risk assessments on Salmonella, 18 on Campylobacterand 16 on Listeria, including completed and on-going studies in both developed and developing countries, as well as those undertaken by FAO / WHO on Salmonella and Campylobacter in broilers. However, it is necessary to recognise that MRA is still in its infancy and the degree of uncertainty is high, indicating that much remains to be done to fill the data gaps and refine the mathematical methods involved. Ultimately, MRA will ensure that public health policies have a sound scientific basis and will be directed towards the most effective control strategies.

\section{References}

Allen VM, Corry JEL, Burton CH, Whyte RT, Mead GC. Hygiene aspects of modern poultry chilling. International Journal of Food Microbiology 2000; 58:39-48.

Arnaut-Rollier I, Vauterin L, De Vos P, Massart DL, Devriese LA, De Zuler L, Van Hoof J. A numerical taxonomic study of the Pseudomonas flora isolated from poultry meat. Journal of Applied Microbiology 1999; 87:15-28.

CAC Principles and Guidelines for the Conduct of Microbiological Risk Assessment. Codex Alimentarius Commission, FAO, Rome, Italy, CAC/GL-30; 1999.

Cavitte JC. Present and future control of food-borne pathogens in poultry; revision of the European Community legislation on zoonoses. In: Proceedings of the XVI European Symposium on the Quality of Poultry Meat 2003; Saint-Brieuc, France v.1 p 46-58.

Corry JEL, Atabay HI. Poultry as a source of Campylobacter and related organisms. Journal of Applied Microbiology 2001; 90:96S114 S.

Corry JEL, James C, O’Neill D, Yaman H, Kendall A, Howell M. Physical methods, readily adapted to existing commercial processing plants, for reducing numbers of campylobacters on raw poultry. International Journal of Medical Microbiology 2003; 293 Suppl., 35:32.

Doyle MP, Schoeni JL. Isolation of Escherichia coli 0157: H7 from retail fresh meats and poultry. Applied and Environmental Microbiology 1987; 53:2394-6.

Federal Register. Pathogen Reduction; Hazard Analysis and Critical Control Point (HACCP) Systems; Final rule. Department of Agriculture: Food Safety and Inspection Service. Federal Register 1996; 61 (144):38806-38989.

Fluckey WM, Sanchez MX, McKee SR, Smith D, Pendleton E, Brashears MM. Establishment of a microbiological profile for an 
air-chilling poultry operation in the United States. Journal of Food Protection 2003; 66:272-9.

Hakkinen M, Schneitz C. Efficacy of a commercial competitive exclusion product against a chicken pathogenic Escherichia coli and E. coli 0157:H7. Veterinary Record 1996; 139:139-141.

Heuvelink AE, Zwartkruis-Nahuis JTM, Van Den Biggelaar FLAM, Van Leeuwen WJ, De Boer E. Isolation and characterization of verocytotoxin-producing Escherichia coli 0157 from slaughter pigs and poultry. International Journal of Food Microbiology 1999; 52: $67-75$.

Kelly LA, Hartnett E, Gettinby G, Fazil A, Snary E, Wooldridge M. Microbial safety of poultry meat: Risk assessment as a way forward. World's Poultry Science Journal 2003; 59:495-508.

Kessel AS, Gillespie IA, O'Brien SJ, Adak GK, Humphrey TJ, Ward LR. General outbreaks of infectious intestinal disease linked with poultry, England and Wales, 1992 - 1999. Communicable Disease and Public Health 2001; 4:171-7.

Mead GC Shelf-life and spoilage of poultry meat, In: Mead GC, editor. Poultry meat processing and quality. Cambridge, UK, Woodhead, 2004. p. 283-303.

Mead GC, Hudson WR, Hinton MH. Effect of changes in processing to improve hygiene control on contamination of poultry carcasses with campylobacter. Epidemiology and Infection 1995; 115:495-500.

Mulder RWAW. Decrease microbial contamination during poultry processing. Poultry Misset 1985 march; 52-5.

Munday D, Coburn H, Snary E. Risk Assessments in the Area of Food Safety, Weybridge, UK: Veterinary Laboratories Agency; 2003.

Ollinger Mueller $V$. The economics of sanitation and process controls in meat and poultry plants. Washington, DC: Unites States Department of Agriculture; 2003. (Agricultural Economics Report no. 817).

Persson $U$, Jendteg $S$. The economic impact of poultry-borne salmonellosis: how much should be spent on prophylaxis? International Journal of Food Microbiology 1992; 15:207- 213.

Pooni GS, Mead GC. Prospective use of temperature function integration for predicting the shelf-life of non-frozen poultry-meat products. Food Microbiology 1984; 1:67-78.

Report. Report on Poultry Meat. Advisory Committee on the Microbiological Safety of Food, HMSO, London, UK; 1996.

Report. Proposal for a Regulation of the European Parliament and of the Council laying down specific rules for the organisation of official controls on products of animal origin intended for human consumption. Working Party of Veterinary Experts (Public Health). Council of the European Union, 7368/2/03; 2003.

Rosenquist $H$, Nielsen NL, Sommer HM, Nørrung B, Christensen BB. Quantitative risk assessment of human campylobacteriosis associated with thermophilic Campylobacter species in chicken. International Journal of Food Microbiology 2003; 83:87-103.
Russell SM. Disinfection of poultry carcasses during scalding and immersion chilling. Turkeys 2003; 51:5-8.

Salmon RL, Farrell ID, Hutchison JGP, Coleman DJ, Gross RJ, Fry NK, Rowe B, Palmer SR. A christening party outbreak of haemorrhagic colitis and haemolytic uraemic syndrome associated with Escherichia coli 0157:H7. Epidemiology and Infection 1989; 103:249-254.

Samadpour M, Ongerth JE, Liston J, Tran N, Nguyen D, Whittam TS, Wilson RA, Tarr PI. Occurrence of Shiga-like toxin producing Escherichia coliin retail fresh seafood, beef, lamb, pork and poultry from grocery stores in Seattle, Washington. Applied and Environmental Microbiology 1994; 60:1038-1040.

Schoeni JL, Doyle MP. Variable colonization of chickens perorally inoculated with Escherichia coli 0157: H7 and subsequent contamination of eggs. Applied and Environmental Microbiology $1994 ; 60: 2958-2962$

Schmidt H, Scheef J, Huppertz HI, Frosch M, Karch H. Escherichia coli0157:H7 and 0157:H(-) strains that do not produce Shiga toxin: phenotypic and genetic characterization of isolates associated with diarrhea and hemolytic-uremic syndrome. Journal of Clinical Microbiology 1999; 37:3491-6.

Shane SM. The changing face of poultry disease: a twenty-year retrospective. World Poultry 2004; 20(7):26-8.

Simmons M, Fletcher DL, Cason, J.A. Berrang, M.E. Recovery of Salmonella from retail broilers by a whole-carcass enrichment procedure. Journal of Food Protection 2003; 66:446-450.

Smerdon WJ, Jones R, McLauchlin J, Reacher M. Surveillance of listeriosis in England and Wales, 1995 - 1999. Communicable Disease and Public Health 2001; 4:188-193.

Stavric S, Buchanan B, Gleeson TM. Intestinal colonization of young chicks with Escherichia coli0157:H7 and other verotoxin-producing serotypes. Journal of Applied Bacteriology 1993; 74:557-563.

Threlfall EJ, Fisher IST, Berghold C, Germer-SmidtP, Tschäpe H, Cormican M. Luzzi I, Schneider F, Wannet W, Machado, J Edwards G. Antimicrobial drug resistance in isolates of Salmonella enterica from cases of salmonellosis in humans in Europe in 2000: results of international multi-centre surveillance. Eurosurveillance 2003; 8:41-5.

Van Pelt W, Van Der See H, Wannet WJB, Van De Giessen AW, Mevius DJ, Bolder NM, Komijn RE, Van Duynhoven YTHP. Explosive increase of Salmonella Java in poultry in the Netherlands: consequences for public health. Eurosurveillance 2003; 8:31-5.

Waldroup AL. Contamination of raw poultry with pathogens World's Poultry Science Journal 1996; 52:7-25.

Williams K, Allen G, Bolton FJ. Survey on the microbiological examination of barbecued chicken. Food Safety Express 2002; 3(3):26-7.

Viehweg SH, Schmitt RE, Schmidt-Lorenz W. Microbial spoilage of refrigerated fresh broilers. VII. Production of off odours from poultry skin by bacterial isolates. Lebensmittel-Wissenschaft undTechnologie 1989; 22:356-367. 